\title{
Effect of quercetin on the anti-tumor activity of cisplatin in EMT6 breast tumor-bearing mice
}

\author{
Hyunju Liư ${ }^{1}$, Jung In Lee ${ }^{2}$, Tae-Gyu Ahn ${ }^{1}$ \\ Departments of ${ }^{1}$ Obstetrics and Gynecology, ${ }^{2}$ Internal Medicine, College of Medicine, Chosun University, Gwangju, Korea
}

\section{Objective}

The purpose of this study was to determine the effect of quercetin on the antitumor activity of cisplatin and its sideeffects.

\section{Methods}

EMT6 cells, a mouse breast cancer cell line, were injected subcutaneously in mice to generate a breast tumor-bearing mouse model. Experimental groups were divided into four groups: control (C), quercetin (Q), cisplatin (CP), and cisplatin+quercetin $(\mathrm{CP}+\mathrm{Q})$.

\section{Results}

The tumor volume of the $\mathrm{CP}+\mathrm{Q}$ group was significantly lower than that of the CP group. Serum blood urea nitrogen and creatinine levels in the $\mathrm{CP}+\mathrm{Q}$ group were lower than those in the $\mathrm{CP}$ group. Renal $\gamma$-glutamyltranspeptidase and alkaline phosphatase activities were significantly higher in the $\mathrm{CP}+\mathrm{Q}$ group than in the $\mathrm{CP}$ group, and the content of renal thiobarbituric acid reactive substance was significantly lower in the $\mathrm{CP}+\mathrm{Q}$ group than that in the $\mathrm{CP}$ group. These results suggested that quercetin and cisplatin synergistically increased cellular toxicity in breast cancer cells and mediated cancer growth inhibition, thereby enhancing the antitumor effect of cisplatin compared to when only cisplatin was administered. Quercetin also reduced renal toxicity, which arose as a potential a side effect of cisplatin.

\section{Conclusion}

The enhanced antitumor effect of cisplatin and decreased renal toxicity after quercetin treatment suggested the applicability of quercetin as an adjuvant for chemotherapeutic agents.

Keywords: Quercetin; Cisplatin; Breast cancer; Renal injury

\section{Introduction}

Chemotherapy can be performed regardless of the type and stage of cancer; therefore, it has been a very useful cancer treatment strategy [1]. However, the presence of chemotherapy-resistant cancer cells along with toxic side effects of chemotherapeutic drugs has limited the application of chemotherapy [2]. A high dose of chemoregimen or a combination of several types of anticancer drugs has been used to overcome the anticancer drug resistance of cancer cells [3]. However, high-dose chemotherapy increases not only the anticancer effect but also its toxic side effects, and thus, it has limitations in terms of its use as a general cancer treatment method [4]. The development of chemotherapy adjuvants that enhance the antitumor activity of chemotherapeutic agents and reduce the toxic side effects of anticancer agents is a very important task in the field of cancer research. Therefore, there have been many studies on potential natural sources of chemotherapy adjuvants [5].

Cisplatin, a platinum-based chemotherapeutic agent, was

Received: 2019.01.09. Revised: 2019.02.25. Accepted: 2019.03.03. Corresponding author: Tae-Gyu Ahn

Department of Obstetrics and Gynecology, College of Medicine, Chosun University, 309 Pilmun-daero, Gwangju 61452, Korea

E-mail:ogatg@chosun.ac.kr

https://orcid.org/0000-0002-5348-2459

Articles published in Obstet Gynecol Sci are open-access, distributed under the terms of the Creative Commons Attribution Non-Commercial License (http://creativecommons. org/licenses/by-nc/3.0/) which permits unrestricted non-commercial use, distribution, and reproduction in any medium, provided the original work is properly cited.

Copyright $\odot 2019$ Korean Society of Obstetrics and Gynecology 


\section{Obstetrics \& Gynecology Science}

Hyunju Liu, et al. Effect of quercetin on cisplatin in mouse model

developed as an anticancer chemotherapeutic agent in the 1970s and has since played an important role in chemotherapy and in the overarching field of cancer treatment [6]. It mediates its antitumor activity by causing inter-strand crosslinking between DNA chains and has been used as a broad-spectrum chemotherapeutic agent for the treatment of various types of solid tumors [7]. Since cisplatin has a high therapeutic effect and is economical, it has been used as a primary chemotherapeutic agent for cancer treatment. However, various toxic side effects, such as renal toxicity, auditory nerve toxicity, and myelosuppression have restricted the use of cisplatin [8]. Renal damage is a very serious toxic adverse effect that occurs in about $30 \%$ of people treated with cisplatin, thereby restricting cisplatin use [9]. Although the mechanism of renal damage induced by cisplatin has not yet been shown, cell damage by free radicals has been known to be involved in the toxic activity of cisplatin [9]. Flavonoids, found in plants, exhibit antioxidant activity and various physiological activities [10]. Quercetin, a flavonoid, is a polyphenolic substance found in citrus, onion, tea, and red wine, and it is known to exhibit physiological activities, such as antitumor, anti-inflammatory, and antiviral activities [11]. Quercetin is already known to inhibit the proliferation and induce apoptosis of breast cancer cells, leading to its antitumor activity [12].

Quercetin ameliorates renal damage caused by cisplatin [13], and quercetin-mediated prevention of cisplatin-induced renal damage does not influence the anticancer effect of cisplatin [14]. However, studies on osteosarcoma cells and human ovarian cancer cell line have demonstrated that quercetin enhanced the antitumor activity of cisplatin $[15,16]$. Thus, quercetin has the potential to be used as an anticancer treatment adjuvant that can enhance antitumor activity or reduce the toxic side effects of anticancer drugs.

Although quercetin has been shown to enhance the cisplatin antitumor efficacy, most studies on quercetin were cellbased and in vivo studies were very few and none of them were on EMT6 treated breast cancer.

Thus, in this study, we observed the effect of quercetin on the anticancer effect and renal toxicity elicited by cisplatin through in vivo experiments using EMT6 breast tumor-bearing mice.

\section{Materials and methods}

\section{Cell culture}

The mouse breast tumor cells (EMT6 cells) used in this experiment were purchased from the American Type Culture Collection. The cells were cultured in McCoy's 5A medium (Gibco BRL, Grand Island, NY, USA) containing 10\% fetal bovine serum, streptomycin $(100 \mathrm{U} / \mathrm{mL})$, and penicillin $(100 \mathrm{U} / \mathrm{mL})$ in a $\mathrm{CO}_{2}$ incubator maintained at $37^{\circ} \mathrm{C}$.

\section{Establishment of breast tumor-bearing mouse model}

The animals used in this experiment were 6-week-old male Balb/c mouse species purchased from Sam Taco Co. (Daejeon, Korea). The mice were bred in a clean environment with a 12-hour light-dark cycle, at temperature of $20 \pm 2{ }^{\circ} \mathrm{C}$, and relative humidity of $60 \pm 5 \%$. Animal experiments were approved by the Institutional Animal Care and Use Committee at Chosun University (approval number: CIACUC 2015-S0004) and carried out according to ethical regulations. The animals were bred one week after purchase, adapted to the environment, and used as tumor-induced animals. Cultured mouse breast cancer cells $\left(2 \times 10^{5}\right.$ cells) were injected subcutaneously to the back of the shaved mice. Then, the volume of the formed tumor mass was measured with a digital caliper (Mitutoyo Korea, Busan, Korea), and it was calculated using the following equation:

Tumor volume $\left(\mathrm{mm}^{3}\right)=\left(\right.$ width $^{2} \times$ length $) / 2$

Mice with a tumor volume of $150-250 \mathrm{~mm}^{3}$ were used as a breast tumor-bearing mouse model for further experiments.

\section{Quercetin and cisplatin administration in breast tumor-bearing mouse model}

Five of the mice with formed tumor mass were assigned to each of the following four groups: control (C) group, cisplatin (CP) group, quercetin (Q) group, and cisplatin+quercetin $(\mathrm{CP}+\mathrm{Q})$ group. The $\mathrm{C}$ group was injected intraperitoneally with $0.2 \mathrm{~mL}$ of phosphate solution for four times at 3-day intervals. Cisplatin $(7 \mathrm{mg} / \mathrm{kg})$ was intraperitoneally injected for four times at 3-day intervals in the $\mathrm{CP}$ group and $\mathrm{CP}+\mathrm{Q}$ group. Quercetin (30 mg/kg) was intraperitoneally injected in the $\mathrm{Q}$ group and $\mathrm{CP}+\mathrm{Q}$ group one hour before cisplatin injection. The size of the tumor mass was measured after every 6 days during the experiment. Three days after the final 


\section{Obstetrics \& Gynecology Science}

Vol. 62, No. 4, 2019

administration of cisplatin and quercetin, mice were anesthetized with $5 \%$ isoflurane, and their blood was collected and the kidneys were removed. Serum was separated and used for blood urea nitrogen (BUN) and creatinine measurement. A kidney from each mouse was used for renal enzyme activity and lipid peroxidation measurement.

\section{Serum blood urea nitrogen and creatinine measurement}

The collected blood was coagulated, and serum was separated and used as for BUN and creatinine measurement. Serum BUN and creatinine levels were measured using a blood auto analyzer (Hitachi 7180; Hitachi, Tokyo, Japan).

\section{Measurement of renal enzyme activity}

A solution of $0.1 \mathrm{M}$ phosphate buffer ( $\mathrm{pH} 7.4$ ) with a volume ten times higher than the kidney tissues ( $/ \mathrm{v} / \mathrm{v}$ ) was added, and the mixture was homogenized with a polytron homogenizer. Then, the mixture was used to evaluate alkaline phosphatase (AP) and $\gamma$-glutamyltranspeptidase (GGT) activity. GGT activity was determined by measuring the amount of p-nitroanilide produced from g-glutamyl-nitroanilide according to the method described by Tate and Meister [17]. AP was determined by measuring the amount of $p$-nitrophenol produced from p-nitrophenyl phosphate according to the method described by Tenenhouse et al. [18]. Protein was measured using a total protein kit (Sigma-Aldrich Chemical Co., St. Louis, MO, USA). The enzyme activity was expressed in $\mu$ moles/mg protein/hour.

\section{Measurement of thiobarbituric acid reactive substance in kidney tissues}

The degree of lipid peroxidation in kidney tissues was evaluated by quantification of thiobarbituric acid reactive substance (TBARS). The kidney tissues were excised, and $0.1 \mathrm{M}$ phosphate buffer ( $\mathrm{pH} 7.4$ ) with 10 times (w/v) higher volume than the tissue was added. Then, the mixture was homogenized with a polytron homogenizer and used for TBARS measurement. The level of TBARS was quantified using the OxiSelect'TM TBARS Assay Kit (Koma Biotech Co., Seoul, Korea), according to the manufacturer's instructions.

\section{Analysis of experimental results}

All measurements were expressed as mean \pm standard deviation, and the results were analyzed by one-way analysis of variance test using the SPSS 12.0 (SPSS Inc., Chicago, IL, USA) statistical program. The significance between samples was compared at the $P<0.05$ level using Duncan's multiple range test.

\section{Results}

\section{Effect of cisplatin and quercetin on tumor growth in EMT6 tumor-bearing mice}

The results of in vivo experiments measuring the effect of quercetin and cisplatin on tumor growth in EMT6 tumorbearing mice are shown in Figs. 1 and 2 . In the $C$ group, tumor volume increased 3.8-fold on day 6 and 8.4-fold on day 12 compared to day 0 . In the Q group, tumor volume increased 3.8-fold on day 6 and 8.4-fold on day 12 compared to day 0 . Thus, there was no significant difference in tumor volume between the $\mathrm{C}$ group and $\mathrm{Q}$ group.

In the CP group, tumor volume increased 3.3-fold on day 6 and 6.1 -fold on day 12 compared to day 0 . Thus, the tumor volume in CP group was $29 \%$ smaller than that of the C group.

In the $\mathrm{CP}+\mathrm{Q}$ group, tumor volume increased 1.8-fold on day 6 and 2.7 -fold on day 12 compared to day 0 . Thus, the tumor volume in $\mathrm{CP}+\mathrm{Q}$ group was $54 \%$ smaller than that of

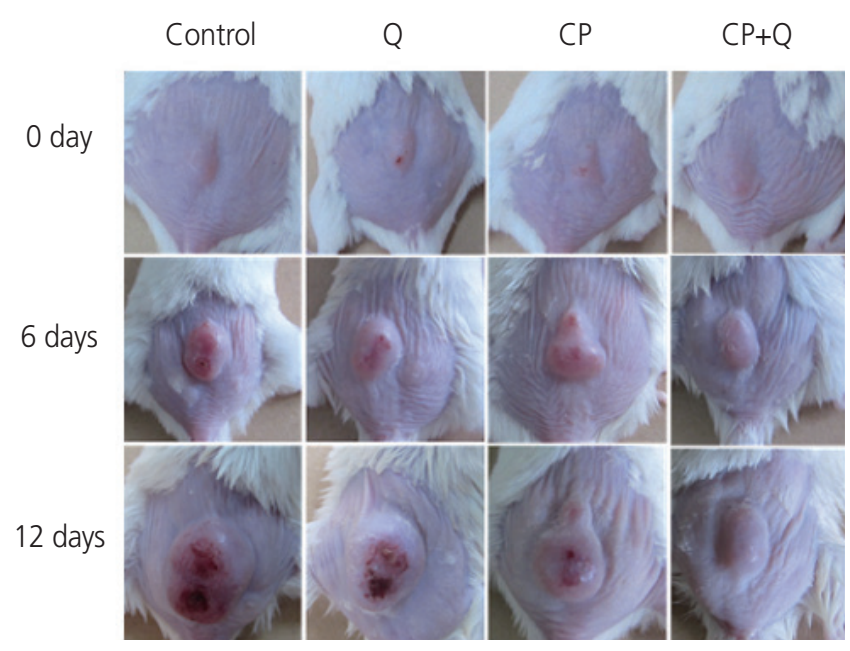

Fig. 1. Photographs of quercetin and cisplatin-treated breast tumor-bearing mice. Breast tumor-bearing mice were treated with cisplatin $(7 \mathrm{mg} / \mathrm{kg}$ ) via intra-peritoneal injection every 3 days for a total of 12 days. Quercetin $(30 \mathrm{mg} / \mathrm{kg}$ ) was injected intraperitoneally 1 hour before cisplatin treatment. Q, quercetin; CP, cisplatin; $\mathrm{CP}+\mathrm{Q}$, cisplatin+quercetin. 


\section{Obstetrics \& Gynecology Science}

Hyunju Liu, et al. Effect of quercetin on cisplatin in mouse model

the CP group, indicating that quercetin and cisplatin synergistically enhanced tumor growth inhibition.

\section{Effect of quercetin and cisplatin on serum blood urea nitrogen and creatinine levels in EMT6 tumor- bearing mice}

Figs. 3 and 4 show serum BUN and creatinine levels after 12 days of cisplatin and quercetin administration in EMT6 tumor-bearing mice. Serum BUN and creatinine levels were not significantly different between the $\mathrm{C}$ group and $\mathrm{Q}$ group. The serum BUN level in the CP group was increased by $248 \%$ compared to that in the $C$ group, and the serum creatinine level was increased by $310 \%$ compared to that in the

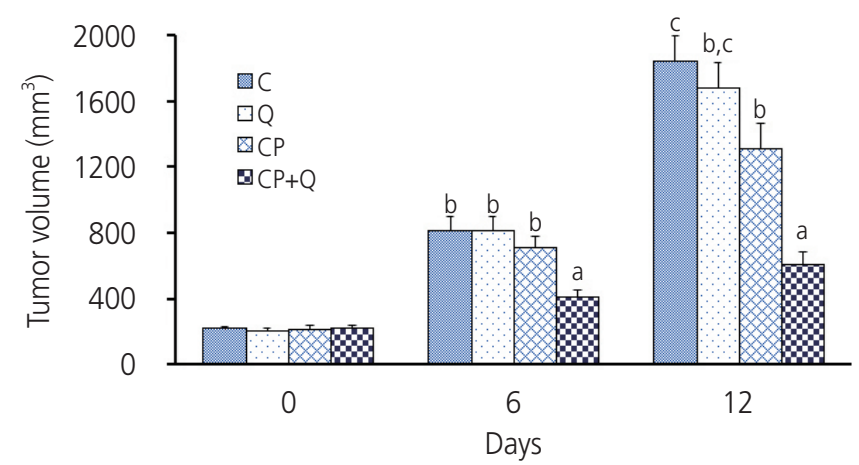

Fig. 2. Effects of quercetin and cisplatin on tumor growth. Values with different superscripts in the same column are significantly different $(P<0.05)$. $C$, control; $Q$, quercetin; $C P$, cisplatin; $C P+Q$, cisplatin+quercetin.

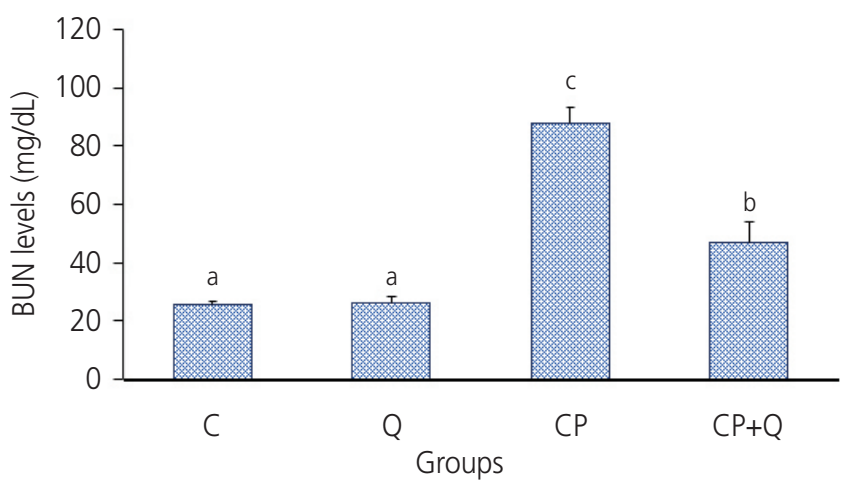

Fig. 3. The effects of dietary quercetin on blood urea nitrogen (BUN) levels in cisplatin-treated breast tumor-bearing mice. The BUN levels were determined 12 days after treatment. Values are expressed as mean \pm standard deviation $(n=5)$. Values with different superscripts are significantly different at $P<0.01$ by Duncan's multiple range test. $C$, control; $Q$, quercetin; $C P$, cisplatin; $C P+Q$, cisplatin+quercetin.
C group. Thus, cisplatin administration increased the serum BUN and creatinine levels, indicating that kidney damage appeared in the CP group. The serum BUN level in the CP+Q group was reduced by $45 \%$ and the serum creatinine level was decreased by $44 \%$ compared to that in the CP group. Thus, the serum BUN and creatinine levels were significantly reduced in the $\mathrm{CP}+\mathrm{Q}$ group compared to those in the $\mathrm{CP}$ group.

\section{Effect of quercetin and cisplatin on renal $\gamma$-glutamyltranspeptidase and alkaline phosphatase activity in EMT6 tumor-bearing mice}

Table 1 shows the renal GGT and AP activity after 12 days of cisplatin and quercetin administration in EMT6 tumor-bearing mice. There was no difference in renal GGT and AP activity

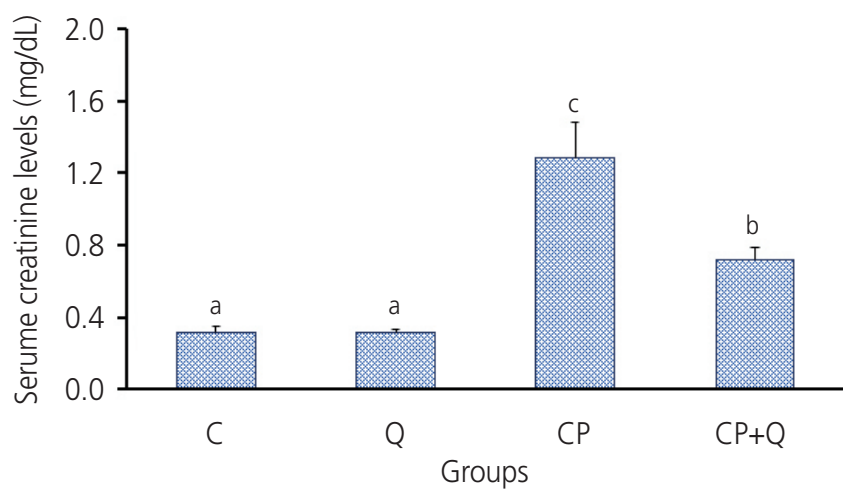

Fig. 4. The effects of quercetin on serum creatinine levels in cisplatin-treated breast tumor-bearing mice. Serum creatinine levels were determined at 12 days after treatment. Values are expressed as mean \pm standard deviation $(n=5)$. Values with different superscripts are significantly different at a level of $P<0.01$ by Duncan's multiple range test. $C$, control; $Q$, quercetin; $C P$, cisplatin; $C P+Q$, cisplatin+quercetin.

Table 1. The effects of quercetin on enzyme activities in the kidney of cisplatin-treated breast tumor-bearing mice

\begin{tabular}{lcc}
\hline Groups & GGT & AP \\
\hline C & $57.3 \pm 4.7^{\mathrm{c}}$ & $16.1 \pm 2.1^{\mathrm{c}}$ \\
Q & $53.8 \pm 5.5^{\mathrm{b}, \mathrm{c}}$ & $15.1 \pm 1.8^{\mathrm{b}, \mathrm{c}}$ \\
$\mathrm{CP}$ & $26.4 \pm 4.7^{\mathrm{a}}$ & $7.1 \pm 1.2^{\mathrm{a}}$ \\
$\mathrm{CP}+\mathrm{Q}$ & $40.1 \pm 5.1^{\mathrm{b}}$ & $12.4 \pm 2.1^{\mathrm{b}}$ \\
\hline
\end{tabular}

Enzyme activities are expressed as moles/mg protein/hour. Values are shown as mean \pm standard deviation $(n=5)$. Different superscripts within the same column are significantly different with $P<0.01$ as analyzed by Duncan's multiple range test.

GGT, $\gamma$-glutamyltranspeptidase; AP, alkaline phosphatase. 


\section{Obstetrics \& Gynecology Science}

Vol. 62, No. 4, 2019

between the $\mathrm{C}$ and Q groups. The renal GGT activity in the CP group was reduced by $55 \%$ and the renal AP activity was decreased by $56 \%$ compared to that in the $\mathrm{C}$ group. Thus, the renal GGT and AP activities were decreased by cisplatin administration, indicating that renal cells were damaged. The renal GGT activity in the CP+Q group was $53 \%$ higher and the renal AT activity was $71 \%$ higher than that in the $\mathrm{CP}$ group. Thus, the renal GGT and AT activities in the $\mathrm{CP}+\mathrm{Q}$ were higher than those in the $\mathrm{CP}$ group.

\section{Effect of quercetin and cisplatin on renal thiobarbituric acid reactive substance level in EMT6 tumor-bearing mice}

The results of renal TBARS content after 12 days of administration of cisplatin and quercetin to EMT6 tumor-bearing mice are shown in Fig. 5. There was no difference in renal TBARS level between the $\mathrm{C}$ and $\mathrm{Q}$ groups. The renal TBARS level in the CP group was increased by $127 \%$ compared to that in the $C$ group, showing that the cisplatin administration increased oxidative damage of renal tissues. The level of renal TBARS in the CP+Q group was $51 \%$ higher than that in the $\mathrm{C}$ group and 33\% lower than that in the CP group, indicating that the cisplatin-induced oxidative damage was reduced in presence of quercetin.

\section{Discussion}

In this study, the effect of quercetin on the antitumor activity

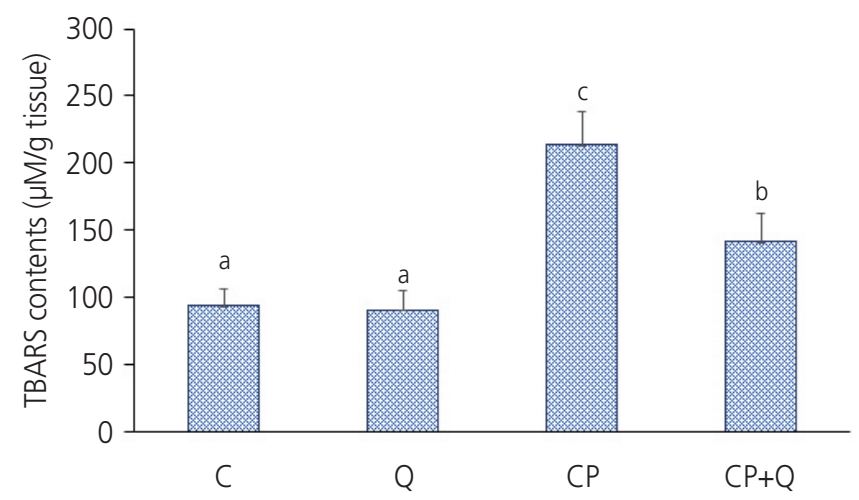

Fig. 5. The effects of quercetin on thiobarbituric acid reactive substance (TBARS) content in kidneys of cisplatin treated tumorbearing mice. Values with different superscripts are significantly different $(P<0.01)$. $C$, control; $Q$, quercetin; $C P$, cisplatin; $C P+Q$, cisplatin+quercetin. and adverse effects of cisplatin was investigated using EMT6 tumor-bearing mice. As a result, the tumor volume of the CP group was decreased by $29 \%$ compared to that of the C group on day 12 , and the tumor volume of $C P+Q$ group was reduced by $54 \%$ compared to that in CP group. Thus, both quercetin and cisplatin synergistically enhanced the tumor growth inhibition. Li et al. [19] demonstrated that quercetin enhanced the therapeutic effect of cisplatin in a 1,2-dimethyl hydrazine-induced colorectal cancer mouse model. On the other hand, Sánchez-González et al. [14] reported that quercetin did not affect antitumor activity of cisplatin in breast tumor cell (13762 Mat B-III) in rat model. In this experiment, cisplatin was injected only once and observed up to 6 days, whereas in our experiment cisplatin was injected for four times at 3-day intervals and observed until 12 days.

Cisplatin was administered three times in a colon cancer mouse model [19] in which quercetin enhanced the anticancer effect of cisplatin.

Therefore, the effect of quercetin seems to be more prominent when administered with multiple doses of cisplatin compared with a single dose.

Renal toxicity induced by cisplatin is an important factor that restricts the use of cisplatin. In this study, serum BUN and creatinine levels in the $C P+Q$ group were lower than those in the C group. GGT and AP activities [20], which are reduced in the case of renal tubular damage, were higher in the $\mathrm{CP}+\mathrm{Q}$ group compared to that in the CP group. The decrease in serum BUN and creatinine levels and the increase in GGT and AP activity in the $\mathrm{CP}+\mathrm{Q}$ group demonstrated that renal damage was decreased in the $C P+Q$ group compared to that in the CP group. Thus, quercetin decreased the renal toxicity induced by cisplatin. Li et al. [19] also reported that quercetin reduced renal toxicity induced by cisplatin in a study using a 1,2-dimethyl hydrazine-induced colorectal cancer mouse model, and Sánchez-González et al. [14] also demonstrated that quercetin reduced renal toxicity induced by cisplatin, which was consistent with the results of this study. In addition, the level of TBARS in renal tissues was decreased in the $\mathrm{CP}+\mathrm{Q}$ group compared to that in the $\mathrm{CP}$ group, showing that the oxidative damage of renal tissue was reduced. Since oxidative damage is known to play an important role in renal toxicity caused by cisplatin, the inhibition of oxidative damage by quercetin is speculated to play an important role in the inhibition of renal toxicity induced by cisplatin. 


\section{Obstetrics \& Gynecology Science}

Hyunju Liu, et al. Effect of quercetin on cisplatin in mouse model

The development of agents that enhance the activity of chemotherapeutic agents or reduce their side effects is vital for implementation of efficient chemotherapy. In this study, quercetin increased the EMT6 cytotoxicity of cisplatin, and in vivo experiments on mice with solid tumors also revealed inhibited tumor growth. Therefore, quercetin enhances the anticancer effect of cisplatin and significantly inhibits renal toxicity induced by cisplatin.

Thus, the results demonstrated the applicability of quercetin as an adjuvant during chemotherapy by cisplatin, which deemed it necessary to conduct follow-up studies.

\section{Acknowledgements}

This study was supported by research funds from Chosun University Hospital 2018.

\section{Conflict of interest}

No potential conflict of interest relevant to this article was reported.

\section{References}

1. Matsuyama R, Reddy S, Smith TJ. Why do patients choose chemotherapy near the end of life? A review of the perspective of those facing death from cancer. J Clin Oncol 2006;24:3490-6.

2. Lønning PE. Molecular basis for therapy resistance. Mol Oncol 2010;4:284-300.

3. Chuthapisith S, Eremin JM, El-Sheemy M, Eremin O. Neoadjuvant chemotherapy in women with large and locally advanced breast cancer: chemoresistance and prediction of response to drug therapy. Surgeon 2006;4:211-9.

4. Vogl DT, Stadtmauer EA. High-dose chemotherapy and autologous hematopoietic stem cell transplantation for metastatic breast cancer: a therapy whose time has passed. Bone Marrow Transplant 2006;37:985-7.

5. Mishra BB, Tiwari VK. Natural products: an evolving role in future drug discovery. Eur J Med Chem 2011;46:4769-807.
6. Hill JM, Loeb E, MacLellan A, Hill NO, Khan A, King JJ. Clinical studies of Platinum Coordination compounds in the treatment of various malignant diseases. Cancer Chemother Rep 1975;59:647-59.

7. Jordan P, Carmo-Fonseca M. Molecular mechanisms involved in cisplatin cytotoxicity. Cell Mol Life Sci 2000;57:1229-35.

8. Hartmann JT, Lipp HP. Toxicity of platinum compounds. Expert Opin Pharmacother 2003;4:889-901.

9. Sharp CN, Siskind LJ. Developing better mouse models to study cisplatin-induced kidney injury. Am J Physiol Renal Physiol 2017;313:F835-41.

10. Kandaswami C, Lee LT, Lee PP, Hwang JJ, Ke FC, Huang $\mathrm{YT}$, et al. The antitumor activities of flavonoids. In Vivo 2005; 19:895-909.

11. Khan F, Niaz K, Maqbool F, Ismail Hassan F, Abdollahi M, Nagulapalli Venkata KC, et al. Molecular targets underlying the anticancer effects of quercetin: an update. Nutrients 2016;8:E529.

12. Aghapour F, Moghadamnia AA, Nicolini A, Kani SN, Barari L, Morakabati $\mathrm{P}$, et al. Quercetin conjugated with silica nanoparticles inhibits tumor growth in MCF-7 breast cancer cell lines. Biochem Biophys Res Commun 2018;500:860-5.

13. Behling EB, Sendão MC, Francescato HD, Antunes LM, Costa RS, Bianchi ML. Comparative study of multiple dosage of quercetin against cisplatin-induced nephrotoxicity and oxidative stress in rat kidneys. Pharmacol Rep 2006;58:526-32.

14. Sánchez-González PD, López-Hernández FJ, Dueñas M, Prieto M, Sánchez-López E, Thomale J, et al. Differential effect of quercetin on cisplatin-induced toxicity in kidney and tumor tissues. Food Chem Toxicol 2017;107:22636.

15. Zhang X, Guo Q, Chen J, Chen Z. Quercetin enhances cisplatin sensitivity of human osteosarcoma cells by modulating microRNA-217-KRAS Axis. Mol Cells 2015;38:638-42.

16. Arzuman L, Beale P, Chan C, Yu JQ, Huq F. Synergism from combinations of tris(benzimidazole) monochloroplatinum(II) chloride with capsaicin, quercetin, curcumin and cisplatin in human ovarian cancer cell lines. Anticancer Res 2014;34:5453-64.

17. Tate SS, Meister A. Y-glutamyl transpeptidase from kidney. In: Meister A, editor. Methods in enzymology. Vol- 


\section{Obstetrics \& Gynecology Science}

Vol. 62, No. 4, 2019

ume 113. New York (NY): Academic Press; 1985. p.40037.

18. Tenenhouse HS, Scriver CR, Vizel EJ. Alkaline phosphatase activity does not mediate phosphate transport in the renal-cortical brush-border membrane. Biochem J 1980;190:473-6.

19. Li QC, Liang Y, Hu GR, Tian Y. Enhanced therapeutic ef- ficacy and amelioration of cisplatin-induced nephrotoxicity by quercetin in 1,2-dimethyl hydrazine-induced colon cancer in rats. Indian J Pharmacol 2016;48:168-71.

20. Fatima S, Arivarasu NA, Mahmood R. Vitamin C attenuates cisplatin-induced alterations in renal brush border membrane enzymes and phosphate transport. Hum Exp Toxicol 2007;26:419-26. 